\title{
Overexpressed cyclophilin B suppresses aldosterone-induced proximal tubular cell injury both in vitro and in vivo
}

\author{
Bin Wang ${ }^{1, *}$, Lilu Lin ${ }^{2, *}$, Haidong Wang ${ }^{3}$, Honglei Guo², Yong Gu${ }^{2}$ and Wei Ding \\ ${ }^{1}$ Division of Nephrology, Huashan Hospital and Institute of Nephrology, Fudan University, Xuhui, Shanghai, P.R. China \\ 2 Division of Nephrology, The Fifth People's Hospital of Shanghai, Fudan University, Shanghai, P.R. China \\ ${ }^{3}$ College of Animal Science and Veterinary Medicine, Shanxi Agricultural University, Taigu, Shanxi, P.R. China \\ * These authors have contributed equally to this work \\ Correspondence to: Wei Ding, email: gump1015@163.com \\ Keywords: tubular cell, oxidative stress, endoplasmic reticulum stress, apoptosis, aldosterone, Pathology Section \\ Received: June 30, 2016 \\ Accepted: September 28, 2016 \\ Published: October 06, 2016
}

\section{ABSTRACT}

The renin-angiotensin-aldosterone system (RAAS) is overactivated in patients with chronic kidney disease. Oxidative stress and endoplasmic reticulum stress (ERS) are two major mechanisms responsible for aldosterone-induced kidney injury. Cyclophilin (CYP) B is a chaperone protein that accelerates the rate of protein folding through its peptidyl-prolyl cis-trans isomerase (PPIase) activity. We report that overexpression of wild-type CYPB attenuated aldosterone-induced oxidative stress (evidenced by reduced production of reactive oxygen species and improved mitochondrial dysfunction), ERS (indicated by reduced expression of the ERS markers glucose-regulated protein 78 [GRP78] and C/-EBP homologous protein [CHOP]), and tubular cell apoptosis in comparison with aldosterone-induced human kidney-2 (HK2) cells. The in vivo study also yielded similar results. Hence, CYPB performs a crucial function in protecting cells against aldosterone-induced oxidative stress, ERS, and tubular cell injury via its PPIase activity.

\section{INTRODUCTION}

Activation of the renin-angiotensin-aldosterone system (RAAS) is a major hallmark in the development and progression of organ damage in chronic kidney disease $(\mathrm{CKD})[1,2]$. In this regard, plasma aldosterone levels and renal expression of the mineralocorticoid receptor (MR) are elevated in patients with CKD and in CKD animal experimental models [3]. We also know that tubular cells are the main target of aldosterone through the regulation of MR, and excessive levels of aldosterone induce tubular cell injury $[4,5]$ and tubulointerstitial fibrosis [6], eventually leading to the progression of CKD.

Knowing the molecular mechanism by which aldosterone causes kidney cell injury will be helpful for improving our understanding of the pathophysiological role of aldosterone in the process of CKD and for exploring new therapeutic targets to cure the injury. An increasing number of studies have suggested that aldosterone induces substantial cell injury in a variety of renal cells, including proximal tubular cells, by activating oxidative stress $[7,8]$ and endoplasmic reticulum stress (ERS) [9]. Oxidative stress is characterized by the increased production of reactive oxygen species (ROS), resulting in mitochondrial dysfunction $(\mathrm{MtD})$ and subsequent apoptosis [10]. The condition caused by ER dysfunctions, where there is aberrant protein folding in the ER lumen, is termed ERS, and we have previously indicated an important role for ROS-mediated ERS in aldosterone-induced human kidney-2 (HK-2) cell apoptosis [8]. Additionally, ERS-induced apoptosis is mainly mediated by $\mathrm{C} /$-EBP homologous protein (CHOP), also referred to as GADD153 (growth arrest and DNA damage 153) [11].

Cyclophilins (CYP) are cellular binding proteins of the immunosuppressive drug cyclosporin A (CsA) $[12,13]$ and are constitutively expressed in most tissues [14]. CYP have peptidyl-prolyl cis-trans isomerase (PPIase) activity, which catalyzes protein folding in cells. Several classic isoforms of CYP, which include CYPA, CYPB, CYPC, and CYPD, have been identified and reside in distinctive cellular locales, apparently providing compartmentspecific functions. CYPB is detected mainly in the ER 
Table 1: Biological parameters of the control, aldosterone, CYPB, and CYPB/aldosterone groups at 4 weeks

\begin{tabular}{|l|c|c|c|c|}
\hline & Control & Aldosterone & CYPB & CYPB/aldosterone \\
\hline Body weight $(\mathrm{g})$ & $26.56 \pm 1.11$ & $26.99 \pm 1.09$ & $25.76 \pm 0.99$ & $25.04 \pm 1.01$ \\
\hline Kidney/body weight ratio $(\mathrm{mg} / \mathrm{g})$ & $11.99 \pm 0.24$ & $13.51 \pm 0.34^{*}$ & $10.98 \pm 0.19$ & $13.360 .31^{\#}$ \\
\hline Albumin/creatinine ratio $(\mu \mathrm{g} / \mathrm{mg})$ & $39.9 \pm 3.5$ & $121.3 \pm 23.4^{*}$ & $38.6 \pm 4.4$ & $75.7 \pm 18.6^{* *}$ \\
\hline Serum aldosterone $(\mathrm{pg} / \mathrm{ml})$ & $69 \pm 5$ & $7855 \pm 780^{*}$ & $71 \pm 6$ & $7538 \pm 701^{\#}$ \\
\hline SBP $(\mathrm{mmHg})$ & $110.5 \pm 3.6$ & $163 \pm 7.6^{*}$ & $106 \pm 3.3$ & $151 \pm 5.7^{\#}$ \\
\hline
\end{tabular}

$* P<0.05$ vs. control values, ${ }^{*} P<0.05$ vs. CYPB, ${ }^{*} * P<0.05$ vs. aldosterone treatment. Control: control/WT; Aldosterone: Aldosterone/WT; CypB: CypB transgenic; CYPB/aldosterone: Aldosterone/ CypB transgenic

lumen, playing a role in protein folding in the ER and performing vital functions to protect cells against ERS [15, 16]. However, there is currently no further information on the function of CYPB in aldosterone-induced kidney injury models.

Here, we focused on the direct effect of CYPB on aldosterone-induced oxidative stress, ERS, and tubular cell injury. Hence, the present study used in vivo and in vitro experiments to address the question of whether CYPB overexpression protects proximal tubular cells against aldosterone-induced injury, and if so, whether it is by improving oxidative stress and ERS.

\section{RESULTS}

\section{Characterization of Cypb transgenic mice}

Cypb mRNA expression was confirmed through real-time PCR of transgenic mouse kidney (Figure

A

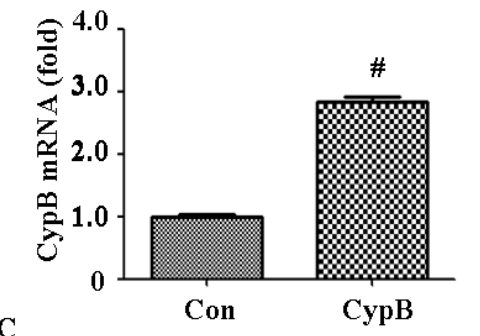

$\mathrm{C}$

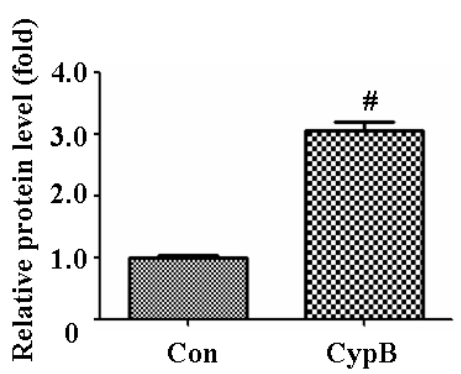

1A). The immunoreactive CYPB was also detected by western blotting in transgenic mouse kidney (Figure 1B). The expression of the Cypb transgene in mouse kidney was 3.1-fold greater than that from the non-transgenic littermates (Figure 1C).

\section{Cypb overexpression improves aldosterone- induced proximal tubular cell apoptosis in vivo}

To obtain in vivo data on the effect of CYPB overexpression on aldosterone-induced proximal tubular cell injury, we used a mouse model with 28-day aldosterone infusion. All physiological and biochemical data are presented in (Table 1). Aldosterone significantly increased the kidney/body weight ratio and urinary protein/creatinine ratio as compared with the control. However, Cypb overexpression did not affect the kidney/ body weight ratio and blood pressure compared with aldosterone/salt-treated animals, but improved the urinary protein/creatinine ratio. Periodic acid Schiff (PAS) staining suggested aldosterone-induced tubular injury as indicated

B

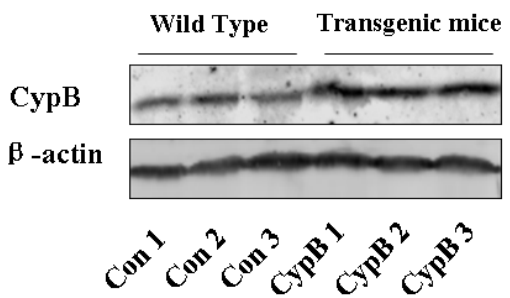

Figure 1: Characterization of Cypb transgenic mouse. A. Real-time PCR analysis of Cypb mRNA expression normalized with Gapdh in wild-type and transgenic mice. B. Whole kidney lysate from three wild-type and transgenic mice each were immunoblotted with antibodies against CYPB and $\beta$-actin. C. Densitometric analysis of CYPB. Data are expressed as mean $\pm \mathrm{SEM}(n=3) ., P<0.01 v s$. Con; Con: control/WT. 
by the increased loss of the brush border; however, the transgenic mice only showed mild injury after aldosterone administration (Figure 2A, 2C). Further examination of renal tissues by terminal deoxyribonucleotidyl transferasemediated dUTP-digoxigenin nick end labeling (TUNEL) assay indicated that aldosterone significantly induced tubular cell apoptosis, which was reduced in $C y p b$ overexpressing mice (Figure 2B and 2D).

\section{Cypb overexpression attenuates aldosterone- induced oxidative stress and ERS in mouse proximal tubular cells}

As oxidative stress is one of the major pathways contributing to aldosterone-induced kidney injury [7], we evaluated ROS levels in the tubular cells. Dihydroethidium (DHE) fluorescence in the tubular cells was markedly increased in the aldosterone group (Figure 3A and $3 \mathrm{~B})$. ERS is another molecular mechanism involved in aldosterone-induced tubular injury, so we evaluated the ERS markers in our animal model. As expected, the expression levels of the major ER chaperone proteins GRP78 and CHOP were increased significantly. However, these changes were improved in Cypb-overexpressing mice (Figure 3C and 3D). Interestingly, aldosterone infusion increased $C y p b$ expression in the kidney tissue (Figure 3C and 3D).

\section{Aldosterone transcriptionally upregulates CYPB}

As aldosterone stimulated CYPB expression in vivo, we then measured whether it also occurs in vitro. Compared with the control cells, 48-h incubation with $10^{-7} \mathrm{M}$ aldosterone significantly increased CYPB mRNA
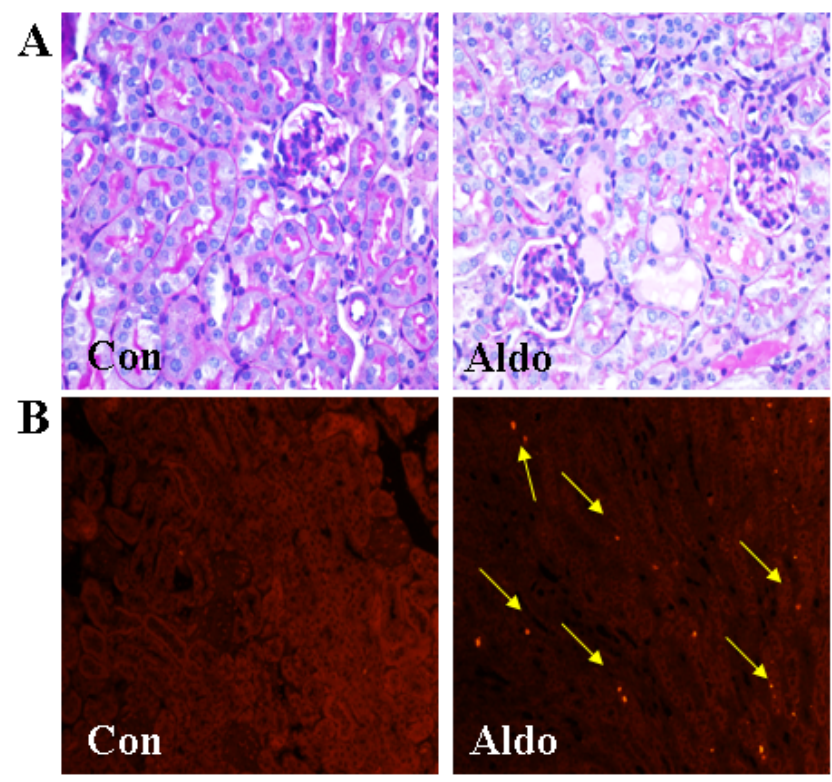

C

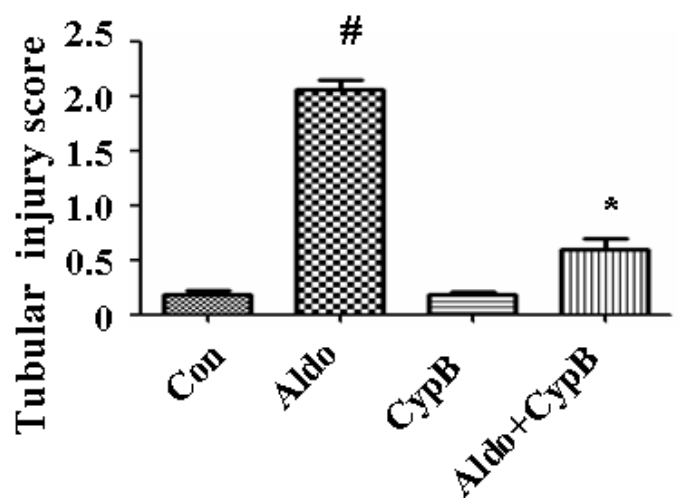

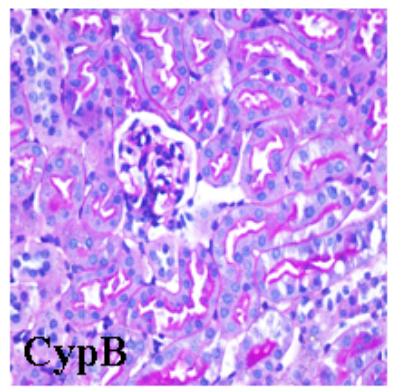
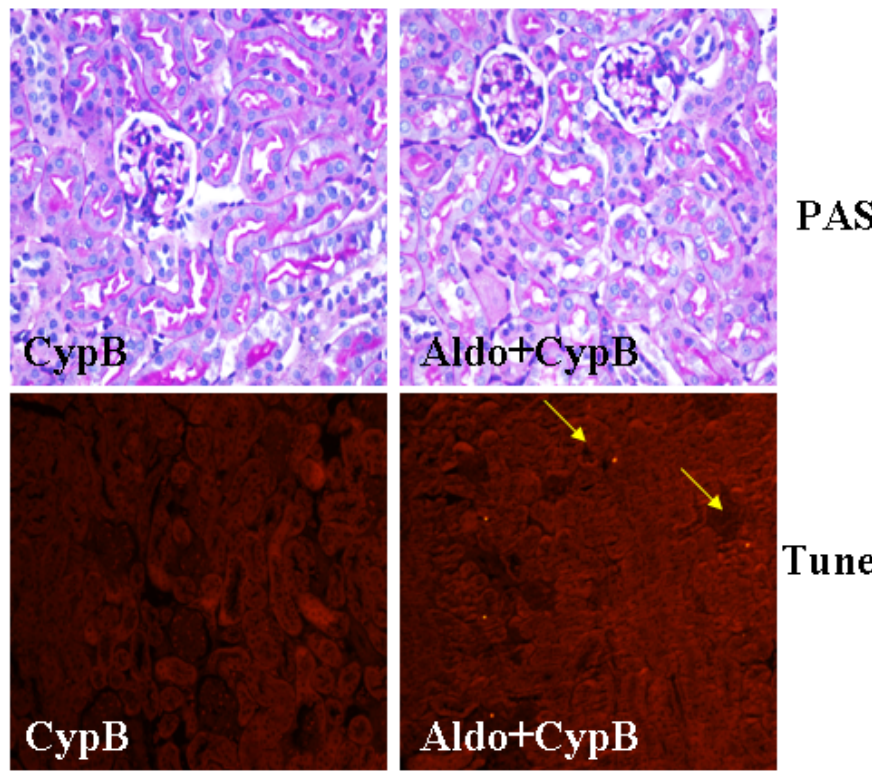

PAS

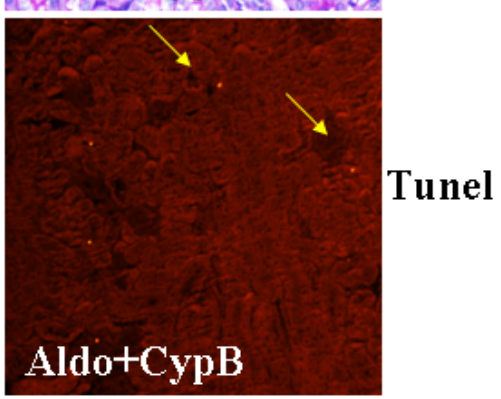

D

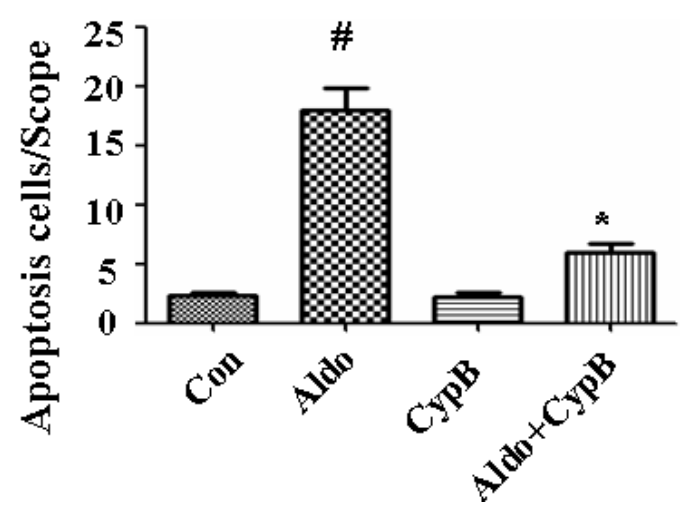

Figure 2: Effects of CYPB overexpression on tubular injury in aldosterone (Aldo)-induced mice. A. Representative light microscopic appearance of PAS-stained glomeruli $(\times 400$ magnification). B. TUNEL assay in renal cortex sections of control and aldosteronetreated mice. Yellow arrows indicate TUNEL-positive tubular cells. C. Scores of tubular injury. D. Bar graph indicating the mean number of TUNEL-positive tubular cells per field ( $\times 200$ magnification). Data are expressed as mean $\pm \operatorname{SEM}(n=6) .{ }^{*} P<0.05 v s$. normal control, ${ }^{*} P<$ 0.05 vs. aldosterone alone. Con: control/WT; Aldo: Aldosterone/WT; CypB: CypB transgenic; Aldo+CypB: Aldosterone/ CypB transgenic 
(Figure 4A) and protein expression (Figure 4B and 4C) in $\mathrm{HK}-2$ cells, which suggests that aldosterone-stimulated CYPB elevation is caused by transcriptional induction. As aldosterone mediates its response through both the MR and non-genomic action, a MR antagonist (Spironolactone, Spi) and actinomycin $\mathrm{D}$ (AD, a transcription inhibitor) were used to characterize the role of MR in aldosteroneinduced CYPB expression. Both Spi and AD abrogated aldosterone-induced CYPB transcription and expression (Figure 4A-4C), indicating that aldosterone-induced CYPB expression is dependent upon the initiation of MRregulated transcriptional events and may serve as a selfcompensative adaptive mechanism.

\section{CYPB overexpression suppresses aldosterone- induced apoptosis and ERS}

To extend our in vivo results to in vitro conditions, we used Annexin V/PI staining to evaluate the effect of
$C Y P B$ overexpression on aldosterone-induced HK-2 cell injury (Figure 5). As expected, $C Y P B$ overexpression significantly attenuated aldosterone-induced apoptosis (Figure 5B and 5C). Similarly, compared with the control group, aldosterone significantly increased Caspase-3 protein. However, CYPB overexpression markedly decreased Caspase-3 levels (Figure 5D and 5E). Incubating HK-2 cells with $10^{-7} \mathrm{M}$ aldosterone for $48 \mathrm{~h}$ also significantly increased the expression levels of the major ER chaperone proteins GRP78 and CHOP (Figure $6 \mathrm{~A}$ and 6B). However, $C Y P B$ overexpression significantly attenuated aldosterone-induced ERS in HK-2 cells.

\section{CYPB siRNA induced ER stress and apoptosis in HK-2 cells}

We next sought to detect whether CYPB will lead to ER stress response and HK-2 cell apoptosis. As shown in Figure 7, HK-2 cells were transfected with scramble

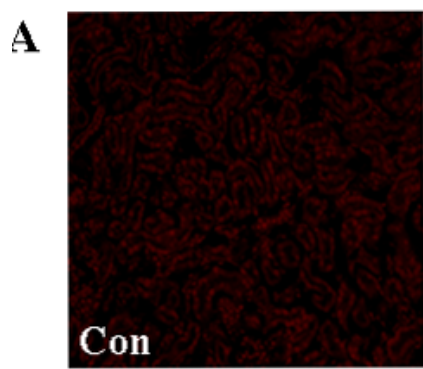

B

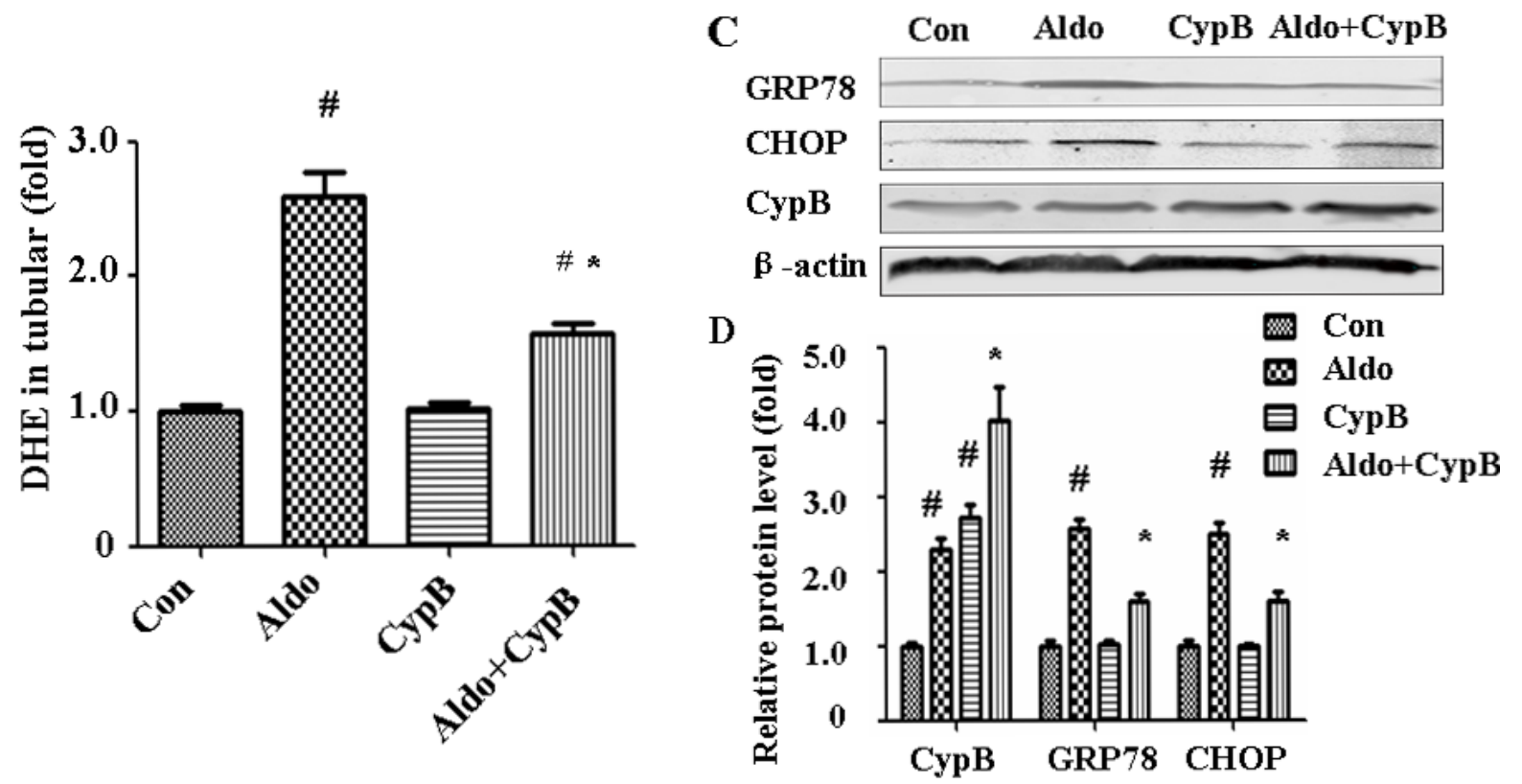

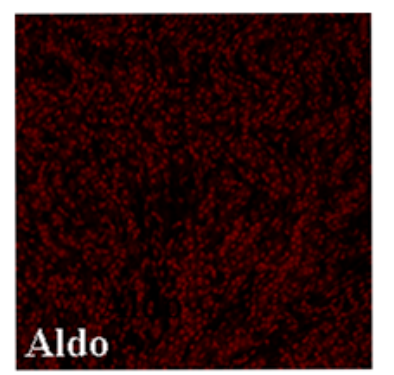
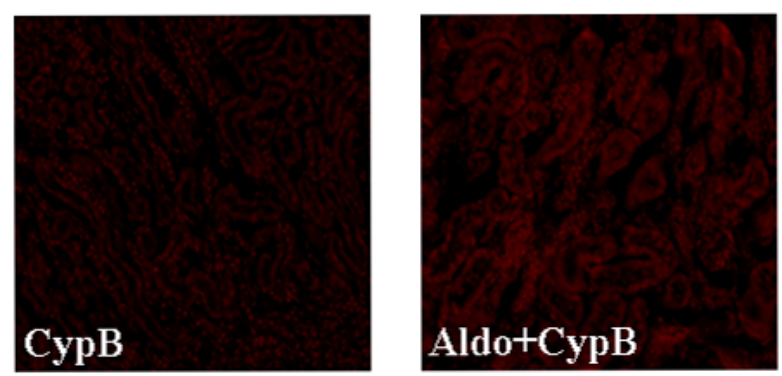

C Con Aldo

Figure 3: Effects of CYPB overexpression on aldosterone (Aldo)-induced oxidative stress and ERS in vivo. A. DHE staining of mouse kidney sections. B. Bar graph indicating the mean DHE intensity per field in mouse tubular cells. C. Whole kidney lysate from the mice were immunoblotted with antibodies against CYPB, GRP78, CHOP, and $\beta$-actin. D. Graphic presentation shows the relative abundances of CYPB, GRP78, and CHOP after normalization with $\beta$-actin. Data are expressed as the mean $\pm \mathrm{SEM} ; n=6$ per group. ${ }^{\sharp} P<0.05$ vs. control, ${ }^{*} P<0.05$ vs. aldosterone group. Con: control/WT; Aldo: Aldosterone/WT; CypB: CypB transgenic; Aldo+CypB: Aldosterone/ CypB transgenic 
siRNA or siRNA against CYPB, and protein expression of GRP 78 and CHOP were evaluated. Treatment with 500 nM CYPB siRNA resulted in a $70 \%$ reduction of CYPB protein expression in HK-2 cells. Compared with control siRNA, CYPB siRNA significantly increased GRP78 and CHOP expression (Figure 7B). CYPB siRNA also was accompanied by HK-2 cell apoptosis (Figure 7C, 7D).
CYPB overexpression suppresses ROS generation and mitochondrial membrane potential (MMP) depolarization

As it has been shown that MtD is associated with aldosterone-induced kidney cell injury [17], we

A

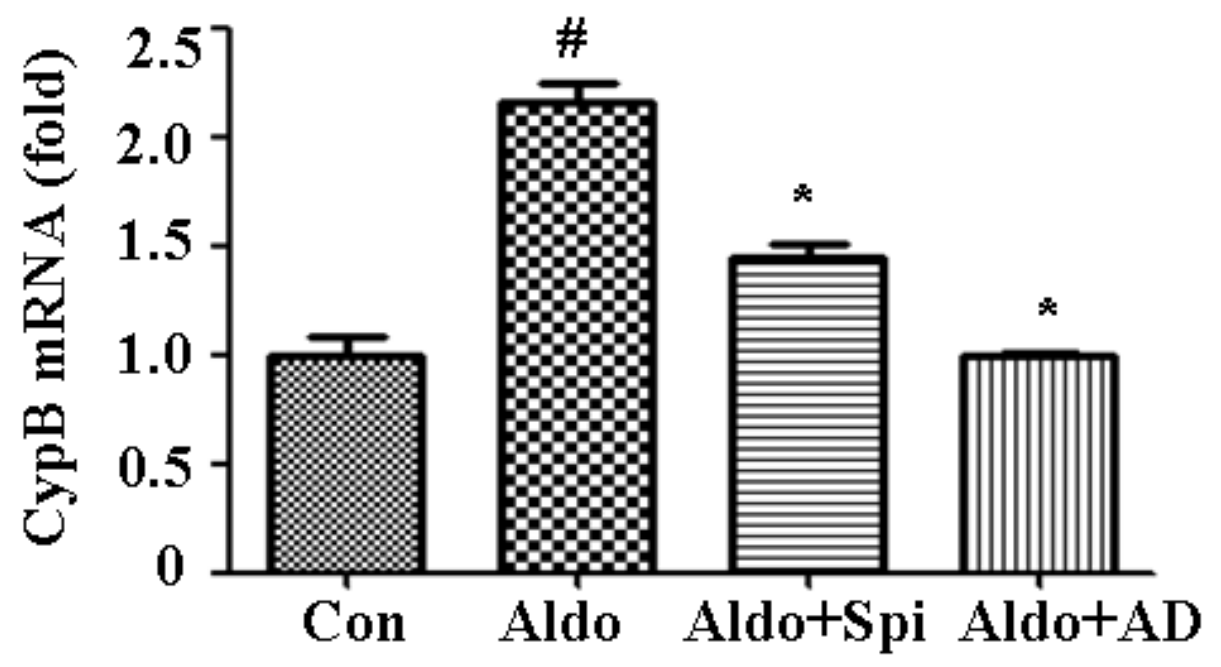

B

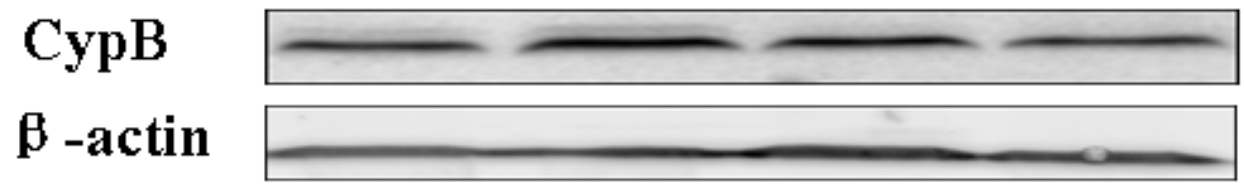

C

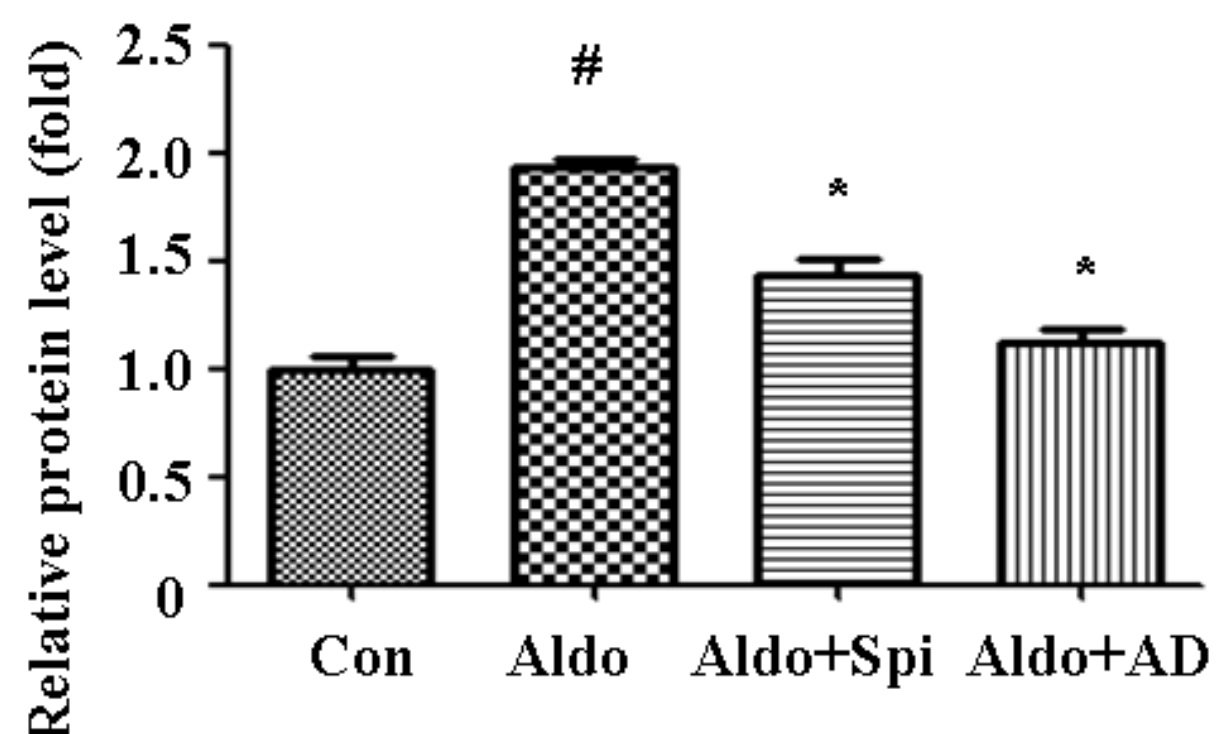

Figure 4: Aldosterone (Aldo) stimulation transcriptionally upregulates CYPB. Equal numbers of HK-2 cells were incubated in medium containing buffer (control), Spi, or AD with or without aldosterone $\left(10^{-7} \mathrm{M}\right)$ for $48 \mathrm{~h}$. A. Real-time PCR analysis of $C Y P B$ mRNA expression normalized with GAPDH. B. Post-treatment western blot analysis of CYPB and $\beta$-actin protein expression. C. Graphic presentation indicates the relative abundance of CYPB after normalization with $\beta$-actin. Results are the mean \pm SEM of three experiments. ${ }^{\#} P<0.05$ vs. normal control, ${ }^{*} P<0.05$ vs. aldosterone alone. Con: control; Spi: Spironolactone; AD: actinomycin D 

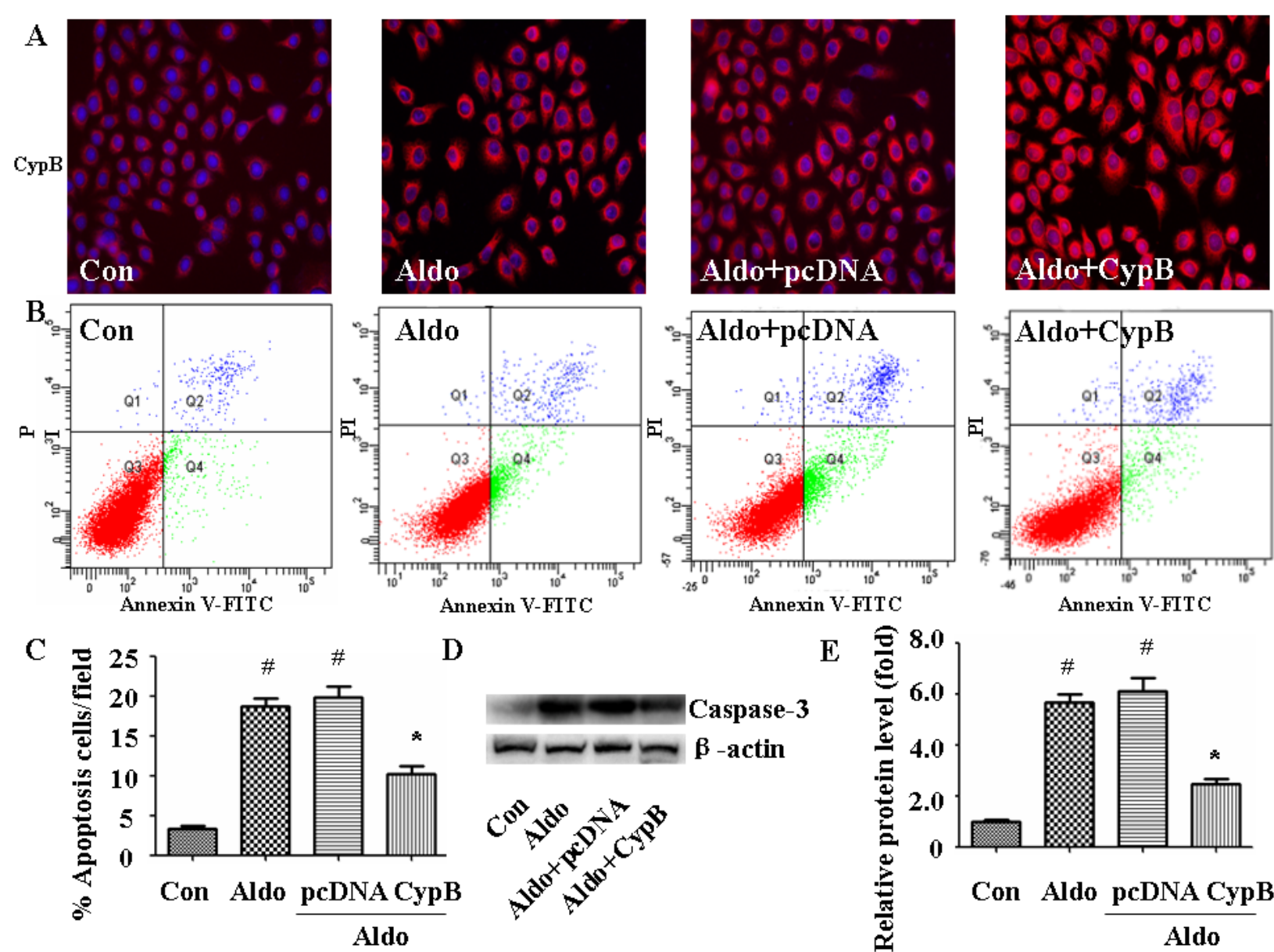

D

$\mathrm{E}$

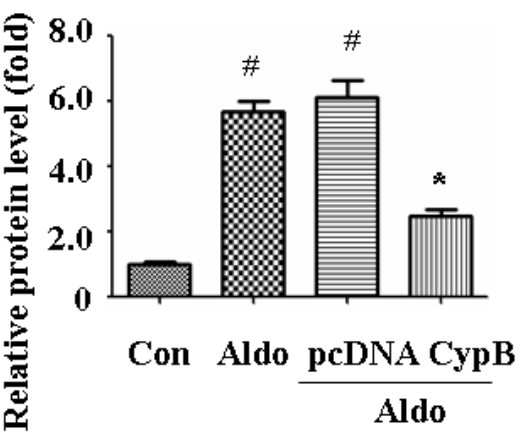

Figure 5: CYPB overexpression suppresses aldosterone (Aldo)-induced apoptosis. A. Equal numbers of HK-2 cells were incubated in medium containing buffer (control), pcDNA empty vector or CYPB vector with or without aldosterone $\left(10^{-7} \mathrm{M}\right)$ for $24 \mathrm{~h}$ and CYPB immunofluorescence staining were performed. B. Post-treatment flow cytometry analysis of Annexin V/PI-stained HK-2 cells. C. Flow cytometry quantification of apoptotic cells. D. Western blot of Caspase-3 protein. E. Densitometric analysis of Caspase-3 expression. Results are the mean \pm SEM of three experiments. ${ }^{\sharp} P<0.05$ vs. normal control, ${ }^{*} P<0.05$ vs. aldosterone alone. Con: control; Aldo: Aldosterone; Aldo+pcDNA: Aldosterone+ pcDNA empty vector; Aldo+ CypB: Aldosterone+ CYPB vector

A

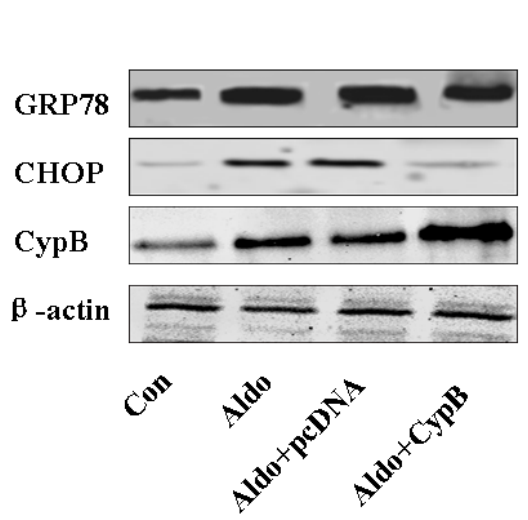

B

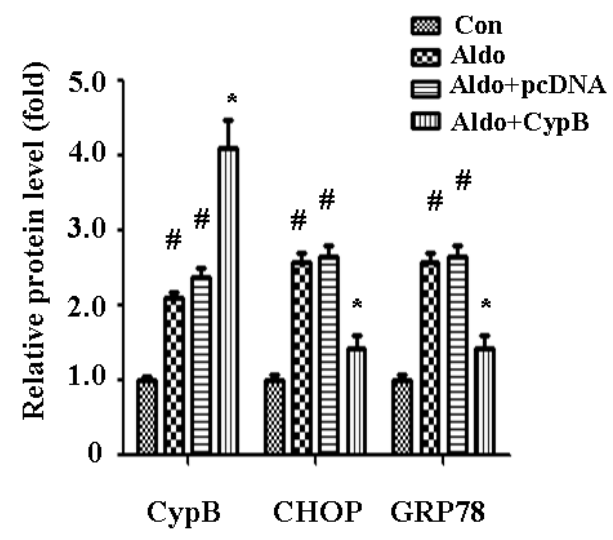

Figure 6: CYPB overexpression suppresses aldosterone (Aldo)-induced ERS. Equal numbers of HK-2 cells were incubated in medium containing buffer (control), pcDNA empty vector or CYPB vector with or without aldosterone $\left(10^{-7} \mathrm{M}\right)$ for $24 \mathrm{~h}$. A. Whole cell lysate was immunoblotted with antibodies against GRP78, CHOP, CYPB, and $\beta$-actin. B. Graphic presentation indicates the relative abundances of GRP78, CHOP, and CYPB after normalization with $\beta$-actin. Results are the mean \pm SEM of three experiments. ${ }^{\#} P<0.05$ $v s$. normal control, ${ }^{*} P<0.05$ vs. aldosterone alone. Con: control; Aldo: Aldosterone; Aldo+pcDNA: Aldosterone+ pcDNA empty vector; Aldo+ CypB: Aldosterone+ CYPB vector 
hypothesized that $C Y P B$ overexpression may protect HK-2 cells against aldosterone-induced injury by improving MtD. We used the independent parameters ROS production and MMP to evaluate MtD. In our study, we found that aldosterone significantly increased MMP collapse (Figure 8) and DHE staining (Figure 9), and $C Y P B$ overexpression significantly attenuated these changes.

\section{DISCUSSION}

The present study suggests that both oxidative stress and ERS participate in aldosterone-induced proximal tubular cell injury. However, CYPB overexpression attenuated all of the changes both in vivo and in vitro. Furthermore, aldosterone induced $C Y P B$ transcription and expression.

RAAS activation is a major hallmark in the development and progression of organ damage in CKD, and aldosterone concentrations are inappropriately high in many patients with CKD and hypertension, as well as in an increasing number of individuals with metabolic syndrome and sleep apnea [18]. Growing evidence suggests that aldosterone induces tubular injury and interstitial inflammation and fibrosis [6, 7]. Consistent with previous studies [19], our in vivo data suggest that aldosterone contributes to tubular cell injury, as indicated by the increased urinary protein/creatinine ratio (Table 1), loss of the brush border, and tubular cell apoptosis. Additionally, aldosterone led to cultured HK-2 cell apoptosis. These results suggest that higher serum levels of aldosterone play an important role in tubular injury in CKD. Hence, knowing the molecular mechanism by which aldosterone damages tubular cells and finding a potential intervention target is helpful for treating this condition.

The ER is one of the largest cell organelles and is responsible for post-synthesis protein modification, folding, and transport. GRP78 is a key ER regulatory protein that functions as a molecular chaperone and plays an important role in the recognition of unfolded proteins
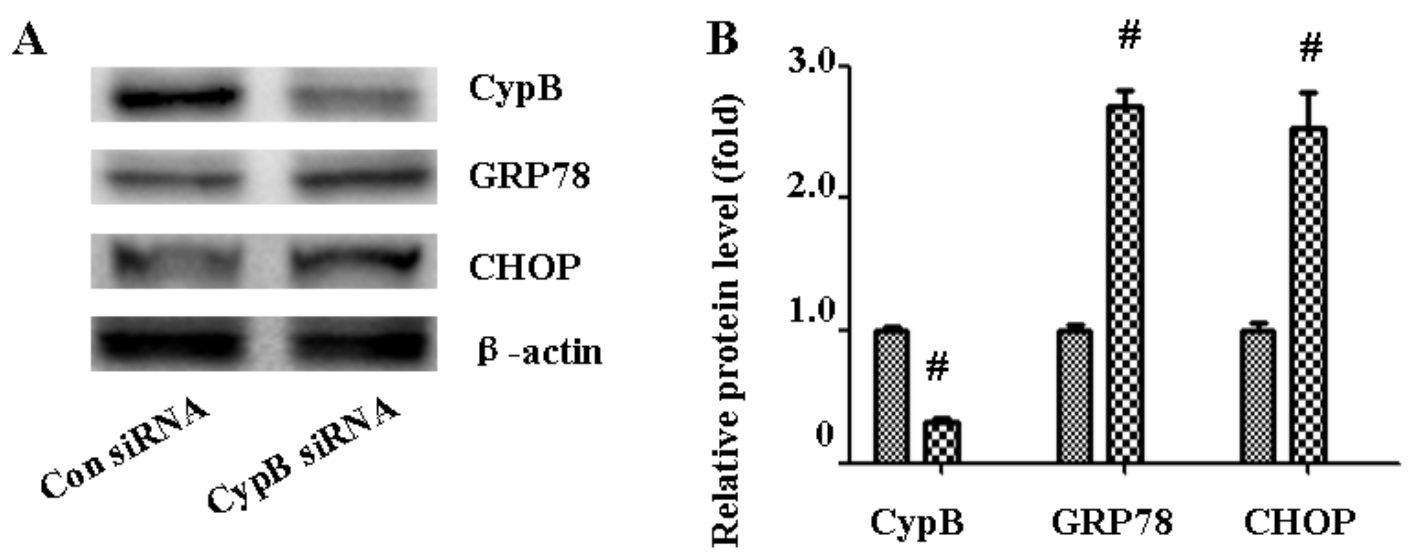

Con SiRNA
CypB siRNA

C

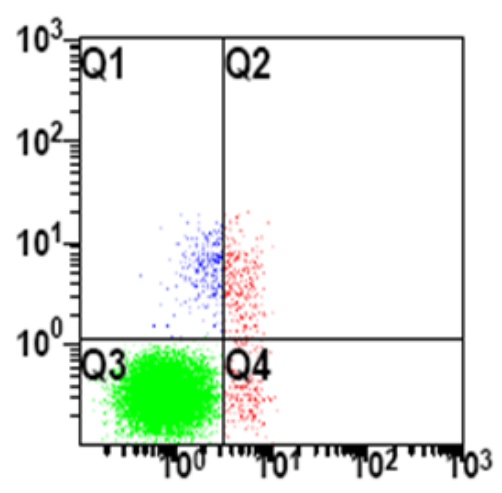

Con siRNA

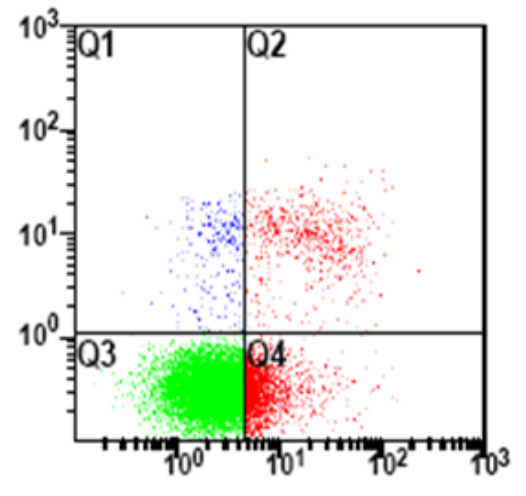

CypB siRNA
D

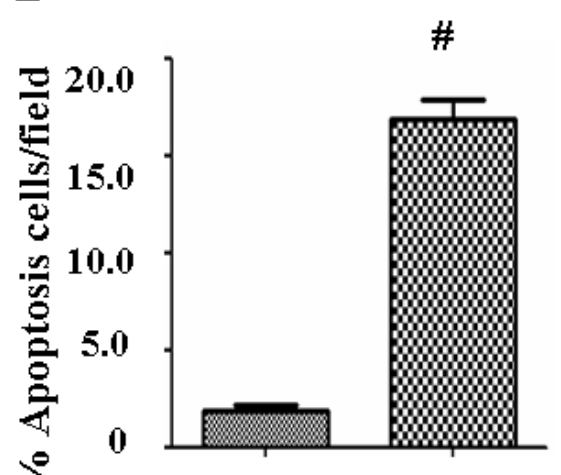

Con siRNA CypB siRNA

Figure 7. CYPB siRNA induced ER stress and apoptosis in HK-2 cells. A. Western blot of CYPB, GRP78, and CHOP. B. Densitometric analysis of CYPB, GRP78 and CHOP expression. C. HK-2 cell apoptosis was measured by flow cytometry. At the end of the incubation period, apoptosis was evaluated in the cells. D. Densitometric analysis of apoptotic HK-2 cells. Results are the mean \pm SEM of three experiments. ${ }^{*}, P<0.01 v s$. Con siRNA; Con siRNA: control scramble siRNA. 
[20]. CHOP is a transcriptional factor that regulates genes involved in ERS-induced apoptosis [21]. Under normal conditions, GRP78 and CHOP are expressed at low levels. When ERS is triggered, GRP78 and CHOP are upregulated to adapt to the stress. If the stress is chronic or consistent, cells will undergo apoptosis [22]. ERS is associated with many renal disorders, including podocyte injury caused by excessive accumulation of secretory protein [23], renal ischemia-reperfusion [24], and apoptotic cell death in chronic CsA-induced nephropathy [25]. ROS produced by oxidative stress interferes with not only cellular redoxdependent reactions but also protein folding capacity, including protein disulfide bonding, ultimately resulting in protein misfolding in the ER [26, 27]. Paradoxically, ERS also increases ROS production in the ER lumen, and alteration of ER $\mathrm{Ca}^{2+}$ homeostasis increases cytosolic $\mathrm{Ca}^{2+}$, thereby stimulating mitochondrial ROS production [16]. Excessive oxidative stress is responsible for MtD, an important pathway leading to apoptosis [28]. The present study results suggest that both oxidative stress and ERS are involved in aldosterone-induced tubular damage both in vivo and in vitro.

CYPB exists in a complex with other molecular chaperones and folding enzymes [29], suggesting its possible role in protecting cells against ERS. Recent researches showed that CYPB played a protective role in various kinds of cells including macrophages, neuroblastoma cells, and H9C2 cells $[16,30,31]$. In this study, overexpression of wild-type CYPB protected tubular cells against aldosterone-induced ERS and apoptosis both in vivo and in vitro. In addition, aldosterone-treated mice had high levels of a glomerular ROS production marker. As expected, wild-type CYPB overexpression reduced the aldosterone-induced oxidative stress both in vivo (Figure 3) and in vitro (Figure 8), indicating that CYPB overexpression attenuates aldosterone-induced tubular injury by suppressing both oxidative stress and ERS. Interestingly, we demonstrate that CYPB is induced in
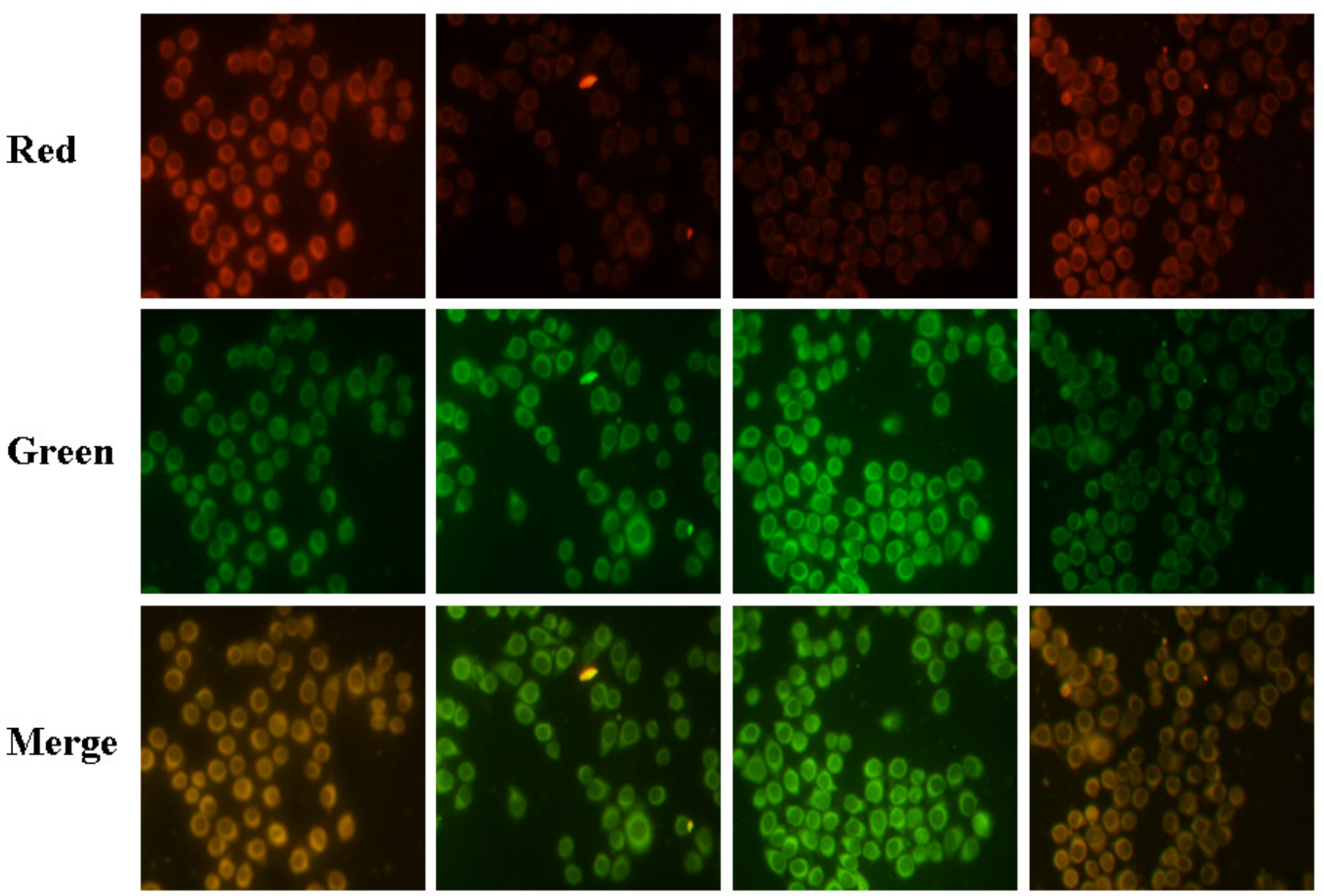

Con

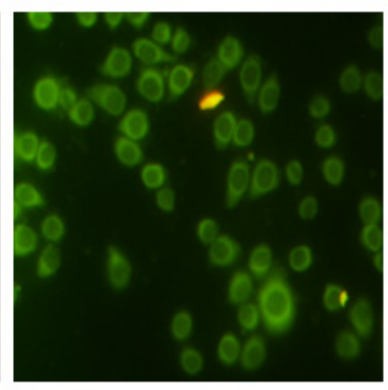

Aldo

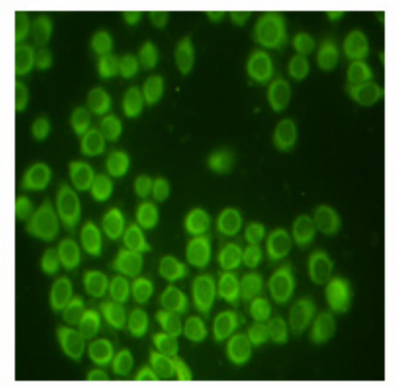

Aldo+pcDNA

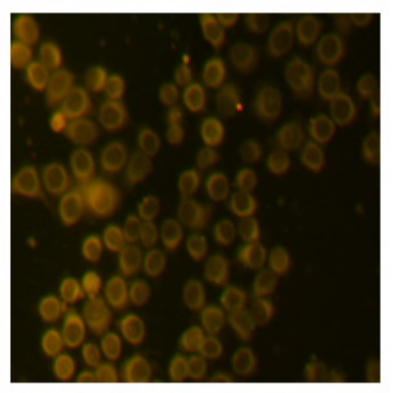

Aldo+CypB

Figure 8: Aldosterone (Aldo) induces mitochondrial membrane potential (MMP) depolarization. Equal numbers of HK-2 cells were incubated in medium containing buffer (control), pcDNA empty vector or CYPB vector with or without aldosterone $\left(10^{-7} \mathrm{M}\right)$ for $24 \mathrm{~h}$. Representative images of HK-2 cells stained with tetrachloro-1, 1', 3, 3'-tetraethylbenzimidazolcarbocyanine iodide (JC-1) $(\times 400$ magnification). Results are presented as the mean \pm SEM $(n=3)$. Con: control; Aldo: Aldosterone; Aldo+pcDNA: Aldosterone+ pcDNA empty vector; Aldo+ CypB: Aldosterone $+\mathrm{CYPB}$ vector 
response to aldosterone stimulation both in vivo and in vitro, suggesting a compensatory adaptive response after stress in tubular cells.

In conclusion, we provide the first evidence that CYPB suppresses excessive RAAS activation-induced oxidative stress and ERS, which may serve as a potential interventional target for improving tubular injury in patients with CKD.

\section{MATERIALS AND METHODS}

\section{Ethical statement}

This investigation has been conducted in accordance with the ethical standards and according to the Declaration of Helsinki and according to national and international guidelines and has been approved by the institutional review board.

\section{Antibodies and reagents}

Aldosterone and anti- $\beta$-actin antibody were purchased from Sigma. Antibodies against CHOP, glucose-regulated protein 78 (GRP78) and Caspase-3 were purchased from Cell Signaling Technology. Anti-CYPB antibodies were obtained from Abcam. All other chemicals were of analytical grade.

\section{Cell culture and transient transfection of HK-2 with CYPB small interfering RNA}

HK-2 cells were grown in Dulbecco's modified Eagle's medium (DMEM)/F12 containing 10\% fetal bovine serum (FBS) and 1\% penicillin/streptomycin (Gibco). The cells were grown at $37^{\circ} \mathrm{C}$ in a humidified $5 \% \mathrm{CO}_{2}$ incubator and subcultured at $60-80 \%$ confluence using $0.05 \%$ trypsin- $0.02 \%$ ethylenediaminetetraacetic acid (EDTA, Gibco). Transient transfection of HK-2 cells

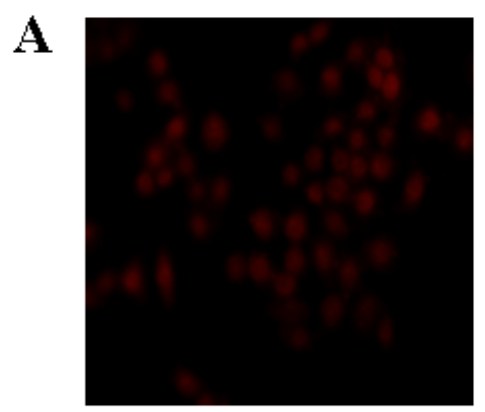

Con

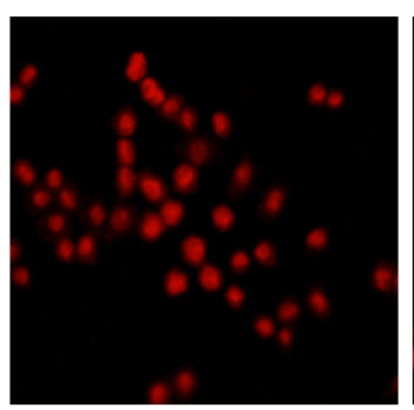

Aldo

B

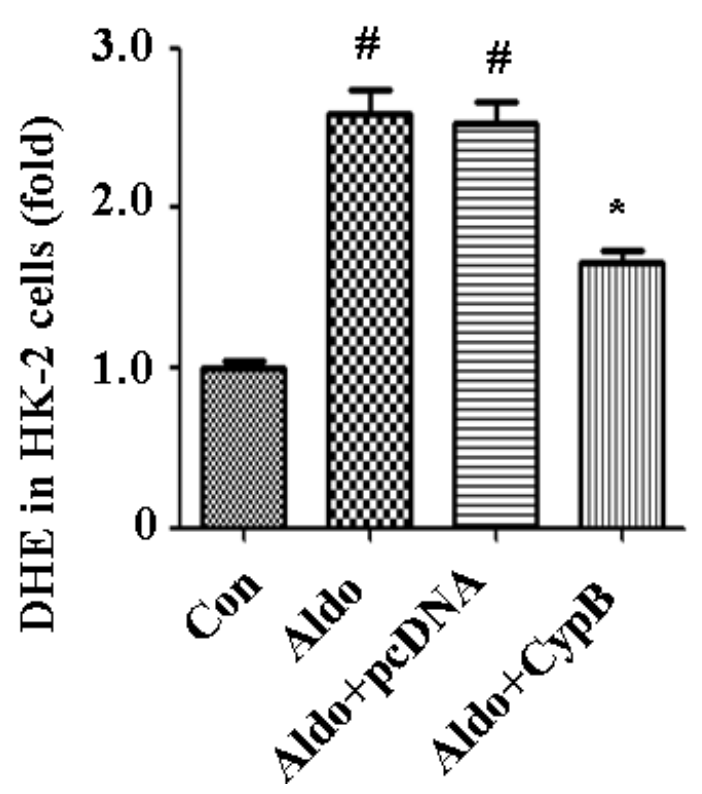

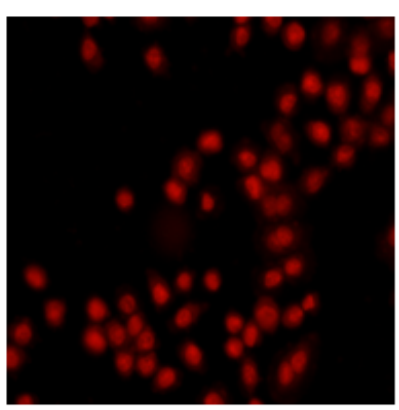

Aldo+pcDNA

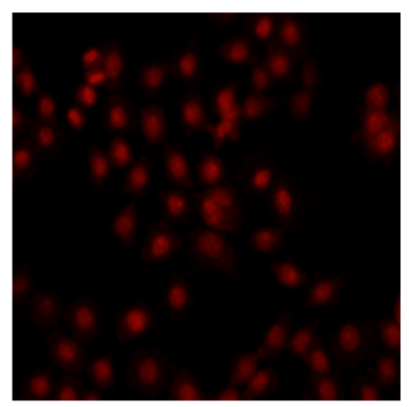

Aldo+CypB

C

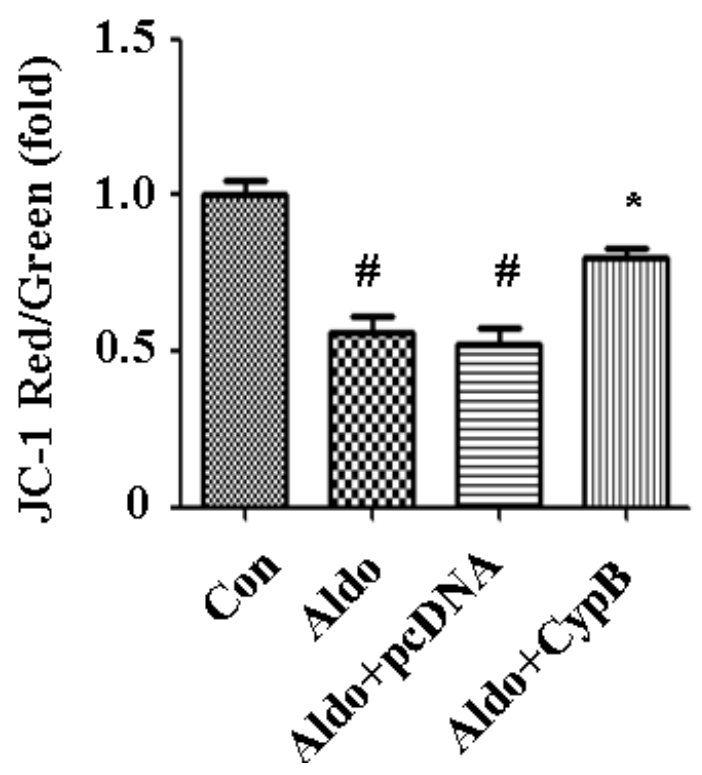

Figure 9: Aldosterone (Aldo) induces ROS production leading to MtD. A. Representative images of HK-2 cells stained with DHE ( $\times 400$ magnification). B., C. DHE and JC-1 fluorescence was quantified by fluorimetry at $24 \mathrm{~h}$. Results are presented as the mean \pm SEM $(\mathrm{n}=3) .{ }^{\#} P<0.05$ vs. normal control, ${ }^{*} P<0.05$ vs. aldosterone alone. Con: control; Aldo: Aldosterone; Aldo+ pcDNA: Aldosterone+ pcDNA empty vector; Aldo+ CypB: Aldosterone+ CYPB vector 
with siRNA was previously demonstrated [32]. HK-2 cells were grown to $60 \%$ confluence and then transfected with 500 nM CYPB siRNA or scramble siRNA (Santa Cruz, CA) using lipofectamine (Invitrogen, CA).

\section{Transient transfection of HK-2 cells with CYPB plasmid}

A full-length human $C Y P B$ gene was generated by PCR and subcloned into the pcDNA3.1-HA mammalian expression vector at the EcoR1/XhoI restriction sites. The pcDNA3.1-HA empty vector was used as the control. Lipofectamine 3000 and plasmids were separately diluted in serum-free medium and incubated at room temperature for $5 \mathrm{~min}$, then mixed and incubated at room temperature for a further $20 \mathrm{~min}$. Aliquots of the transfection mixture were added to cell culture dishes. The medium was replaced with fresh DMEM/F12 containing 10\% FBS and cultured for another $24 \mathrm{~h}$ after 4 -h transfection. The cells were then serum-deprived for $24 \mathrm{~h}$ before being treated with or without aldosterone.

\section{Real-time PCR}

Total RNA was isolated from HK-2 cells using an RNA isolation kit (Invitrogen) according to the manufacturer's instructions, and was eluted with RNasefree water. Reverse transcription was performed using a First Strand cDNA Synthesis Kit (Fermentas) according to the manufacturer's protocols. Real-time PCR was performed using THUNDERBIRD SYBR qPCR Mix reagent (TOYOBO, QPS-201) in a real-time PCR system (Stratagene). The following primer pairs were used: CYPB (sense 5'-GGGGACTCTGGTGTTGGAA-3', anti-sense 5'-CGCTCCTATTGTGGCTTTGT-3') and glyceraldehyde-3-phosphate dehydrogenase (GAPDH) (sense 5'-TCTTTTGCGTCGCCAGCCGAG-3', anti-sense 5'-TCCCGTTCTCAGCCTTGACGGT-3').

\section{Propidium iodide-conjugated annexin V-fluorescein isothiocyanate (FITC) staining}

Annexin $\mathrm{V}$ is a $\mathrm{Ca}^{2+}$-dependent phospholipid binding protein with a high affinity for phosphatidylserine, which is externalized on the surface of the cell membrane during the progression of apoptosis. HK-2 cell apoptosis was performed according to the Annexin V/propidium iodide method (BD Biosciences, San Diego, CA) as previously described [32]. After resuspending the cell suspension evenly, one drop of suspension was placed on glass slides and the cells were observed under fluorescence microscopy; apoptosis was measured in the remaining cells using a FACScan flow cytometer (Epics Altra, Beckman Coulter).

\section{DHE staining}

Oxidative stress was determined and quantified using microfluorimetry detection of DHE oxidation to ethidium. Superoxide $\left(\mathrm{O}^{2}\right)$ selectively oxidizes this reaction and is an essential precursor to harmful cellular oxidants such as the hydroxyl radical (OH-) and peroxynitrite (ONOO-). Cells were cultured in black 96well plates and the growth medium was replaced with 5 $\mu \mathrm{M}$ DHE in serum-free DMEM/F12 and incubated for $30 \mathrm{~min}$. Fluorescence intensity was measured at $536 \mathrm{~nm}$ excitation and $610 \mathrm{~nm}$ emission (Synergy Mx Multi-Mode Microplate Reader; BioTek). Fluorescence values were normalized to protein content for the corresponding wells and expressed as DHE fluorescence per $\mu \mathrm{g}$ protein.

\section{Western blot analysis}

Harvested HK-2 cells and mouse kidney tissue were lysed in sodium dodecyl sulfate (SDS) sample buffer containing $150 \mathrm{mM} \mathrm{NaCl}, 0.1 \%$ Triton X-100, 0.5\% deoxycholate, $0.1 \%$ SDS, $50 \mathrm{mM}$ Tris- $\mathrm{HCl}(\mathrm{pH} 7.0)$, and $1 \mathrm{mM}$ EDTA. Western blot detection of protein expression was carried out according to established protocols. The primary antibodies used were as follows: GRP78 (1:1000), CHOP (1:1000), CYPB (1:1000), Caspase-3 (1:1000) and $\beta$-actin (1:10000). Densitometric analysis was performed using Quantity One software (Bio-Rad). The relative intensity of each band was normalized to that of $\beta$-actin.

\section{Transgenic cypb mice}

The study protocols were reviewed and approved by the Institutional Animal Care and Use Committee at Fudan University, China. PRP.ExBi-EF1 $\alpha$-cyclophilinBIRES-eGFP was microinjected into the pronuclei of fertilized C57BL/6 mouse eggs that were then transferred to the oviducts of pseudopregnant foster mothers. The founder Cyclophilin B transgenic mouse was generated on a C57BL6-DBA mixed background. The mice used in this research were backcrossed six times to a C57BL6 genetic background. Genotyping was performed by PCR using the following transgene PCR primers: forward $(\mathrm{F})$ : 5'-AGATACACCTGCAAAGGCGGCACAA-3' and reverse (R): 5'-GTGAACAGCTCCTCGCCCTTGCTC-3' (for $C y p b$ coding sequence), and the internal control PCR primers F: 5'-ACTCCAAGGCCACTTATCACC-3' and R: 5'-ATTGTTACCAACTGGGACGACA-3' (for the endogenous mouse $A c t b$ [ $\beta$-actin] locus); tail DNA was used as the template. All experiments used mice hemizygous for the Cypb transgene from a single line (Cypb mice) or their non-transgenic littermates. 


\section{Animal model}

All mice were uninephrectomized and fed $1 \%$ $\mathrm{NaCl}$ with or without aldosterone infusion $(0.75 \mu \mathrm{g} / \mathrm{h}$, subcutaneously) for 4 weeks. Systolic blood pressure (SBP) was measured in conscious mice using tail-cuff plethysmography (BP-98A; Softron) at weeks 4 during the treatment period. Twenty-four hour urine samples were collected after a 24-h acclimatization period in the metabolic cages. Urinary protein excretion was determined using enzyme-linked immunosorbent assay (ELISA) kits (Exocell). Urine and plasma creatinine levels were analyzed using an assay kit (Jiancheng).

\section{DHE and PAS staining in kidney sections}

Frozen kidney segments in OCT compound were cut into 5- $\mu \mathrm{m}$ sections and stained with DHE (50 $\mu \mathrm{M}$, Invitrogen) for $30 \mathrm{~min}$ at room temperature in the dark. DHE fluorescent images were visualized under fluorescence microscopy at $\times 200$ magnification. The average DHE fluorescence intensities of tubular cells were calculated from at least six random fields from each sample. Kidneys were also fixed with $10 \%$ formalin, embedded in paraffin, sectioned into $5 \mu \mathrm{m}$ slices and then stained with periodic acid-Schiff (PAS). Degree of renal tubular injury was graded onto a scale from 0 to 4 as follows; 0 : normal; 1 : mild, involvement of less than $25 \%$; 2 : moderate, involvement of $25 \%-50 \%$; 3 : severe, involvement of 50\%-75\%; 4 : extensive damage involving more than $75 \%$ of the cortex. At least 20 glomerulis were analyzed in each group [33].

\section{Analysis of tubular cell apoptosis in renal tissue}

Apoptotic tubular cells were detected in frozen kidney sections using a FITC-labelled in situ TUNEL assay (Roche Molecular Biochemicals) according to the manufacturer's protocol. The deparaffinized sections were incubated with $50 \mu \mathrm{l}$ TUNEL reaction mixture for $60 \mathrm{~min}$ at $37^{\circ} \mathrm{C}$ in the dark. For quantification, $10-20$ fields were randomly selected from each section, and the number of TUNEL-positive cells was counted per millimeter [32].

\section{Statistical analyses}

Data are expressed as the mean \pm standard error of the mean (SEM). Comparisons between groups were performed with one-way analysis of variance (ANOVA) followed by Dunnett's multiple comparison tests or Student's $t$-test. $P<0.05$ was considered statistically significant.

\section{ACKNOWLEDGMENTS}

This work was supported by grants from the National Natural Science Foundation of China (81300590, 81400714, 81570661).

\section{CONFLICTS OF INTEREST}

The authors declare that there is no conflict of interest.

\section{REFERENCES}

1. Jugdutt BI. Expanding Saga of the Renin-Angiotensin System: The Angiotensin II Counter-Regulatory AT2 Receptor Pathway. Circulation. 2015; 131: 1380-1383.

2. Mavrakanas TA, Gariani K, Martin PY. Mineralocorticoid receptor blockade in addition to angiotensin converting enzyme inhibitor or angiotensin II receptor blocker treatment: an emerging paradigm in diabetic nephropathy: a systematic review. European Journal of Internal Medicine. 2014; 25: 173-176.

3. Schrier RW, Masoumi A, Elhassan E. Aldosterone: role in edematous disorders, hypertension, chronic renal failure, and metabolic syndrome. Clinical Journal of the American Society of Nephrology. 2010; 5: 1132-1140.

4. Fan YY, Kohno M, Hitomi H, Kitada K, Fujisawa Y, Yatabe J, Yatabe M, Felder RA, Ohsaki H, Rafiq K, Sherajee SJ, Noma T, Nishiyama A, Nakano D. Aldosterone/Mineralocorticoid receptor stimulation induces cellular senescence in the kidney. Endocrinology. 2011; 152: 680-688.

5. Whaley-Connell AT, Habibi J, Nistala R, DeMarco VG, Pulakat L, Hayden MR, Joginpally T, Ferrario CM, Parrish AR, Sowers JR. Mineralocorticoid receptor-dependent proximal tubule injury is mediated by a redox-sensitive mTOR/S6K1 pathway. American Journal of Nephrology. 2012; 35: 90-100.

6. Wang B, Ding W, Zhang M, Li H, Gu Y. Rapamycin attenuates aldosterone-induced tubulointerstitial inflammation and fibrosis. Cell Physiol Biochem. 2015; 35 : 116-125.

7. Cheema MU, Poulsen ET, Enghild JJ, Hoorn EJ, Fenton RA, Praetorius J. Aldosterone and angiotensin II induce protein aggregation in renal proximal tubules. Physiol Rep. 2013; 1: e00064. doi: 10.1002/phy2.64

8. Ding W, Yang L, Zhang M, Gu Y. Reactive oxygen species-mediated endoplasmic reticulum stress contributes to aldosterone-induced apoptosis in tubular epithelial cells. Biochem Biophys Res Commun. 2012; 418: 451-456.

9. Kim H, Moon SY, Kim JS, Baek CH, Kim M, Min JY, Lee SK. Activation of AMP-activated protein kinase inhibits ER stress and renal fibrosis. Am J Physiol Renal Physiol. 2015; 308: F226-F236. 
10. Bartz RR, Suliman HB, Piantadosi CA. Redox mechanisms of cardiomyocyte mitochondrial protection. Front Physiol. 2015; 6: 291.

11. Lekstrom-Himes J, Xanthopoulos KG. Biological role of the CCAAT/enhancer-binding protein family of transcription factors. J Biol Chem. 1998; 273: 28545-28548.

12. Hong F, Lee J, Song JW, Lee SJ, Ahn H, Cho JJ, Ha J, Kim SS. Cyclosporin A blocks muscle differentiation by inducing oxidative stress and inhibiting the peptidyl-prolylcis-trans isomerase activity of cyclophilin A: cyclophilin A protects myoblasts from cyclosporin A-induced cytotoxicity. FASEB J. 2002; 16: 1633-1635.

13. Choi KJ, Piao YJ, Lim MJ, Kim JH, Ha J, Choe W, Kim SS. Overexpressed cyclophilin A in cancer cells renders resistance to hypoxia- and cisplatin-induced cell death. Cancer Res. 2007; 67: 3654-3662.

14. Andreeva L, Heads R, Green CJ. Cyclophilins and their possible role in the stress response. Int J Exp Pathol. 1999; 80: 305-315.

15. Stocki P, Chapman DC, Beach LA, Williams DB. Depletion of cyclophilins B and C leads to dysregulation of endoplasmic reticulum redox homeostasis. J Biol Chem. 2014; 289: 23086-23096.

16. Kim J, Choi TG, Ding Y, Kim Y, Ha KS, Lee KH, Kang I, Ha J, Kaufman RJ, Lee J, Choe W, Kim SS. Overexpressed cyclophilin B suppresses apoptosis associated with ROS and $\mathrm{Ca} 2+$ homeostasis after ER stress. J Cell Sci. 2008; 121: 3636-3648.

17. Yuan Y, Chen Y, Zhang P, Huang S, Zhu C, Ding G, Liu B, Yang T, Zhang A. Mitochondrial dysfunction accounts for aldosterone-induced epithelial-to-mesenchymal transition of renal proximal tubular epithelial cells. Free Radic Biol Med. 2012; 53: 30-43.

18. Brown NJ. Aldosterone and end-organ damage. Curr Opin Nephrol Hypertens. 2005; 14: 235-241.

19. Ogawa Y, Mukoyama M, Yokoi H, Kasahara M, Mori K, Kato Y, Kuwabara T, Imamaki H, Kawanishi T, Koga K, Ishii A, Tokudome T, Kishimoto I, Sugawara A, Nakao K. Natriuretic peptide receptor guanylyl cyclase-A protects podocytes from aldosterone-induced glomerular injury. J Am Soc Nephrol. 2012; 23: 1198-1209.

20. Yoshida H, Haze K, Yanagi H, Yura T, Mori K. Identification of the cis-acting endoplasmic reticulum stress response element responsible for transcriptional induction of mammalian glucose-regulated proteins. Involvement of basic leucine zipper transcription factors. J Biol Chem. 1998; 273: 33741-33749.

21. Inagi R. Endoplasmic reticulum stress as a progression factor for kidney injury. Curr Opin Pharmacol.2010; 10: 156-165.

22. Vembar SS, Brodsky JL. One step at a time: endoplasmic reticulum-associated degradation. Nat Rev Mol Cell Biol. 2008; 9: 944-957.

23. Inagi R, Nangaku M, Onogi H, Ueyama H, Kitao Y,
Nakazato K, Ogawa S, Kurokawa K, Couser WG, Miyata $\mathrm{T}$. Involvement of endoplasmic reticulum (ER) stress in podocyte injury induced by excessive protein accumulation. Kidney Int. 2005; 68: 2639-2650.

24. Cybulsky AV, Takano T, Papillon J, Bijian K. Role of the endoplasmic reticulum unfolded protein response in glomerular epithelial cell injury. J Biol Chem. 2005; 280: 24396-24403.

25. Han SW, Li C, Ahn KO, Lim SW, Song HG, Jang YS, Cho YM, Jang YM, Ghee JY, Kim JY, Kim SH, Kim J, Kwon OJ, Yang CW. Prolonged endoplasmic reticulum stress induces apoptotic cell death in an experimental model of chronic cyclosporine nephropathy. Am J Nephrol. 2008; 28: 707-714.

26. Moungjaroen J, Nimmannit U, Callery PS, Wang L, Azad N, Lipipun V, Chanvorachote P, Rojanasakul Y. Reactive oxygen species mediate caspase activation and apoptosis induced by lipoic acid in human lung epithelial cancer cells through Bcl-2 down-regulation. J Pharmacol Exp Ther. 2006; 319: 1062-1069.

27. Das A, Banik NL, Ray SK. Garlic compounds generate reactive oxygen species leading to activation of stress kinases and cysteine proteases for apoptosis in human glioblastoma T98G and U87MG cells. Cancer. 2007; 110: 1083-1095.

28. Yuan Y, Huang S, Wang W, Wang Y, Zhang P, Zhu C, Ding G, Liu B, Yang T, Zhang A. Activation of peroxisome proliferator-activated receptor-gamma coactivator 1alpha ameliorates mitochondrial dysfunction and protects podocytes from aldosterone-induced injury. Kidney Int. 2012; 82: 771-789.

29. Meunier L, Usherwood YK, Chung KT, Hendershot LM. A subset of chaperones and folding enzymes form multiprotein complexes in endoplasmic reticulum to bind nascent proteins. Mol Biol Cell. 2002; 13: 4456-4469.

30. Oh Y, Jeong K, Kim K, Lee YS, Jeong S, Kim SS, Yoon KS, Ha J, Kang I, Choe W. Cyclophilin B protects SHSY5Y human neuroblastoma cells against MPP(+)-induced neurotoxicity via JNK pathway. Biochem Biophys Res Commun. 2016; 478: 1396-402.

31. Marcant A, Denys A, Melchior A, Martinez P, Deligny A, Carpentier M, Allain F. Cyclophilin B attenuates the expression of TNF- $\alpha$ in lipopolysaccharide-stimulated macrophages through the induction of B cell lymphoma-3. J Immunol. 2012; 189: 2023-2032.

32. Ding W, Guo H, Xu C, Wang B, Zhang M, Ding F. Mitochondrial reactive oxygen species-mediated NLRP3 inflammasome activation contributes to aldosteroneinduced renal tubular cells injury. Oncotarget. 2016; 7: 17479-17491. doi:10.18632/oncotarget.8243.

33. Sun Y, Zhang Y, Zhao D, Ding G, Huang S, Zhang A, Jia Z. Rotenone remarkably attenuates oxidative stress, inflammation, and fibrosis in chronic obstructive uropathy. Mediators Inflamm. 2014; 2014:670106. doi: 10.1155/2014/670106. 